OPEN ACCESS

Edited by:

Jean Challacombe

Twist Bioscience, United States

Reviewed by: Jeanne Marie Fair,

Los Alamos National Laboratory

(DOE), United States

Eirini Christaki,

University of Cyprus, Cyprus

*Correspondence:

Juan David Ramírez

juand.ramirez@urosario.edu.co

tThese authors have contributed equally to this work and share first authorship

Specialty section

This article was submitted to Infectious Diseases - Surveillance,

Prevention and Treatment,

a section of the journa

Frontiers in Medicine

Received: 17 March 2021

Accepted: 29 June 2021

Published: 23 July 2021

Citation:

Rincón-Acevedo CY,

Parada-García AS, Olivera MJ, Torres-Torres F, Zuleta-Dueñas $L P$ Hernández C and Ramírez JD (2021)

Clinical and Epidemiological Characterization of Acute Chagas

Disease in Casanare, Eastern Colombia, 2012-2020.

Front. Med. 8:681635

doi: 10.3389/fmed.2021.681635

\title{
Clinical and Epidemiological Characterization of Acute Chagas Disease in Casanare, Eastern Colombia, 2012-2020
}

\section{Claudia Yaneth Rincón-Acevedo 1,2†, Andrea Stella Parada-García 1,2t, Mario Javier Olivera ${ }^{3}$, Fernando Torres-Torres ${ }^{4}$, Liliana Patricia Zuleta-Dueñas ${ }^{4}$, Carolina Hernández ${ }^{1}$ and Juan David Ramírez ${ }^{1 *}$}

${ }^{1}$ Centro de Investigaciones en Microbiología y Biotecnología-UR, Facultad de Ciencias Naturales, Universidad del Rosario, Bogotá, Colombia, ${ }^{2}$ Maestría en Salud Pública, Escuela de Medicina y Ciencias de la Salud, Universidad del Rosario, Bogotá, Colombia, ${ }^{3}$ Grupo de Parasitología, Instituto Nacional de Salud, Bogotá, Colombia, ${ }^{4}$ Secretaría de Salud de Casanare, Yopal, Colombia

Background: Chagas disease (CD), caused by the protozoan Trypanosoma cruzi, is considered a public health problem in Latin America. In Colombia, it affects more than 437,000 inhabitants, mainly in Casanare, an endemic region with eco-epidemiological characteristics that favor its transmission. The objective of this study was to describe the clinical and epidemiological characteristics of the cases of acute CD in Casanare, eastern Colombia, in the period 2012-2020.

Methods: In the present study, 103 medical records of confirmed cases of acute CD were reviewed. The departmental/national incidence and fatality were compared by year; the climatological data of mean temperature, relative humidity, and precipitation per year were reviewed and plotted at IDEAM (Colombian Meteorology Institute) concerning the number of cases of acute CD per month, and it was compared with the frequency of triatomines collected in infested houses by community surveillance. Univariate, bivariate, and multivariate analyses were performed, comparing symptoms and signs according to transmission routes, complications, and age groups.

Results: The incidence was 3.16 cases per 100,000 inhabitants, and the fatality rate was $20 \%$ in the study period. The most frequent symptoms included: fever $98.1 \%$, myalgia $62.1 \%$, arthralgia $60.2 \%$, and headache $49.5 \%$. There were significant differences in the frequency of myalgia, abdominal pain, and periorbital edema in oral transmission. The main complications were pericardial effusion, myocarditis, and heart failure in the group over 18 years of age. In Casanare, Tcl Discrete Typing Unit (DTU) has mainly been identified in humans, triatomines, and reservoirs such as opossums and dogs and TcBat in bats. An increase in the number of acute CD cases was evidenced in March, a period when precipitation increases due to the beginning of the rainy season.

Conclusions: The results corroborate the symptomatic heterogeneity of the acute phase of $\mathrm{CD}$, which delays treatment, triggering possible clinical complications. In 
endemic regions, clinical suspicion, diagnostic capacity, detection, and surveillance programs should be strengthened, including intersectoral public health policies for their prevention and control.

Keywords: Trypanosoma cruzi, acute Chagas disease, DTU, outbreaks, Casanare, Colombia

\section{BACKGROUND}

Chagas disease (CD), caused by the parasite Trypanosoma cruzi, continues to be a significant cause of morbidity, disability, and mortality, mainly in Latin America. It is estimated that it affects 6-7 million people globally, constituting an emerging threat for several non-endemic countries $(1,2)$. The disease has an acute phase and a chronic phase characterized by an unpredictable clinical course, ranging from the absence of symptoms to severe diseases with cardiovascular, gastrointestinal, or neurological involvement (3). Trypanosoma cruzi presents high genetic variability given that six Discrete Typing Units (DTUs) have been identified that are distributed throughout the American continent (TcI-TcVI) and an additional DTU associated mainly with anthropogenic bats called TcBat described in Brazil, Colombia, Panama, and Ecuador $(4,5)$. Additionally, genetic variability has been detected in TcI DTU, finding parasites associated with sylvatic transmission cycles and a genotype mainly associated with domestic transmission $\mathrm{TcI}_{\text {Dom }}$ (6). Consequently, the clinical forms and the severity of the manifestations are diverse between regions and individuals, considering the host's immune response and a plethora of T. cruzi virulence factors (7).

Clinically, the acute phase of $\mathrm{CD}$ can be asymptomatic or present non-specific symptoms that include prolonged fever and general malaise, estimating that only $1-2 \%$ of cases in this phase are identified $(4,8)$; mortality can range between 10 and $80 \%$, which is widely variable depending on the diagnosis and timely treatment (2). Additionally, in the severe form of the acute phase, complications such as myocarditis, heart failure, arrhythmias, atrioventricular blocks, and to a lesser extent, meningoencephalitis may occur, situations that increase mortality (9). When the disease is not diagnosed or treated in the acute phase, the patient evolves into the chronic phase, with the risk of developing irreversible chronic Chagas heart disease characterized by complex ventricular and atrial arrhythmias, bradyarrhythmias, atrioventricular block, apical aneurysm, ventricular dysfunction, and heart failure (1012) and digestive complications such as megaesophagus and megacolon (13).

\footnotetext{
Abbreviations: IDEAM, Instituto de Hidrología, Meteorología y Estudios Ambientales; SD, Standard deviation; DTU, Discrete Typing Units; T. cruzi, Trypanosoma cruzi; INS, National Institute of Health; R. prolixus, Rhodnius prolixus; SIVIGILA, Public Health Surveillance System; UPGD, Primary Data Generating Units; IPS, Health Service Provider Institutions; DANE, National Administrative Department of Statistics; T. maculata, Triatoma maculata; P. geniculatus, Panstrongylus geniculatus; T. dimidiata, Triatoma dimidiata; PCR, Polymerase Chain Reaction; qPCR, quantitative Polymerase Chain Reaction; ELISA, Enzyme Immunoassay; IFAT, Immunofluorescence antibody test.
}

Among the various transmission routes of the disease, the vector and oral routes stand out, the latter associated with acute outbreaks with a reported lethality for Latin America between 1 and $35 \%(14,15)$. In some countries of the Southern Cone, such as Brazil, Venezuela, Bolivia, Ecuador, Peru, Argentina, and French Guyana (16), cases of acute CD due to vector transmission and oral outbreaks have been described due to contamination of food with feces of wild triatomines or with secretions from reservoirs. Colombia has also been an important scene of acute Chagas outbreaks, which had increased since 1992 when the first outbreak was identified. The departments of Norte de Santander, Magdalena, Santander, Putumayo, Arauca, Cesar, Antioquia, Chocó, Atlántico and Casanare have reported various outbreaks and isolated cases (17). Despite the high number of oral transmission outbreaks, there are failures in the clinical care of patients given the non-specificity of the symptoms, the clinical and epidemiological ignorance of the disease, which translates into low suspicion of it and affects the presentation of complications and fatality (4).

In Colombia, it is estimated that more than 437,000 infected inhabitants and around 5 million are at risk of acquiring CD (18). The department of Casanare in the Colombian Orinoquia is endemic for $\mathrm{CD}$ and has ecoepidemiological characteristics that favor the transmission of the disease. According to the National Institute of Health (INS) of Colombia, in $201740.3 \%$ of chronic cases and $20 \%$ of acute cases in the country were identified in Casanare. The situation in 2018 was similar to 2017, while in 2019, 50.9\% of acute CD cases in the country came from Casanare (19). This department has reported outbreaks of oral transmission with the lethality of up to $50 \%$ and outbreaks associated with occupational exposure with a significant number of cases $(20,21)$. Currently, Colombia has a program to interrupt the domiciliary vector transmission of $T$. cruzi by Rhodnius prolixus, which means that oral transmission may increase and, with this, the presence of acute cases $(22,23)$.

In Casanare, ten triatomine species (Hemiptera: Reduviidae) have been reported, where $R$. prolixus and Triatoma maculata stand out, the first with presence in 17 of the 19 municipalities $(24,25)$. Likewise, abundant populations of sylvatic $R$. prolixus have been identified associated with native palms Attalea butyracea and palms introduced in agro-industrial crops such as Elaeis guineensis with high rates of natural infection by T. cruzi (24). A high presence of $R$. prolixus infected with T. cruzi has been shown in homes in rural areas, which increases in the low rainfall season and decreases in the months of higher rainfall $(26,27)$. On the other hand, Casanare is the department of the country with the highest number of acute $\mathrm{CD}$, both isolated cases and outbreaks; between 2012 and 2020, 8 outbreaks of presumed oral transmission were reported, and acute cases have been reported in $52.6 \%(10 / 19)$ of the municipalities. 
The insufficient knowledge of the epidemiology and clinical presentation of the disease has been derived from case reports and small series of cases. These are the product of different investigations but are not part of the routine epidemiological surveillance of the event. To close the knowledge gap on this little-known and devastating infection, we present an extensive series of cases of acute infections by $T$. cruzi confirmed by the laboratory in the National Public Health Surveillance System in the period 2012-2020, from one of the most endemic departments of Colombia. The results of this study will permit plan health services, guide decision-makers, developing health policies that improve detection and increase awareness of this disease.

\section{METHODS}

\section{Ethics Approval}

This project was approved by the ethics committee of Universidad del Rosario Act number 426 from Jul 30, 2020.

\section{Methodological Design}

A retrospective, observational and descriptive case series study was carried out from the review of medical records of patients from Casanare notified to the Public Health Surveillance System - SIVIGILA- with acute CD in 2012-2020. The National Public Health Surveillance System (SIVIGILA), regulated in Colombia in 2006, is responsible for the objective, systematic and constant observation and analysis process of health events, supporting the orientation, planning, execution, monitoring, and evaluation of public health practice. SIVIGILA has the Primary Data Generating Units (UPGD), which correspond to Health Service Provider Institutions (IPS) in which cases of the various diseases (including CD) object of public health surveillance are detected and reported (28). A systematic literature review was carried out to verify circulating DTUs in the department of Casanare. Additionally, the database of vectors obtained from community surveillance was further obtained.

\section{Study Area}

The department of Casanare is located in the Colombian Orinoquía, with 381,554 inhabitants (National Administrative Department of Statistics, DANE 2019) distributed in 19 municipalities, of which $75.2 \%$ of the population resides in the municipal capitals. The annual average temperature varies from 6 to $27^{\circ} \mathrm{C}$. Extremes of drought and humidity characterize the climate during the year; there is a rainy period with abundant rainfall between April to November and a dry or summer period from December to March; relative humidity is between 60 and $90 \%$, and it has three types of landscapes that range from 100 meters above sea level to 3,800 meters above sea level. Ninetyfive percentage of the department has a warm, humid climate on the foothills of the eastern mountain range and the flat zone (29). Its landscape is characterized by extensive savannas of grasslands, shrubs, industrial crops of rice and African palm, as well as patches of palm forests on the banks of rivers, streams, wetlands, and lagoons. $57 \%$ of the department comprises flooded savannas where numerous rivers of the Orinoco River basin flow. The most important economic activities are cattle ranching, agriculture, and mining (30); most rural dwellings are immersed in landscape matrices whose main structural component are wild palms. This area provides biological, ecological, and environmental conditions, which favor the ecoepidemiological cycles of the parasite T. cruzi (27).

According to the 2005 DANE estimate, $13.36 \%$ of the population lives in inadequate housing, 5.61\% with inadequate services, $17.36 \%$ in critical overcrowding, and there is a housing deficit of $47,3 \%$, this figure refers to homes with housing shortages both due to qualitative and quantitative deficits (29).

\section{INFORMATION SOURCES}

\section{Human Patients}

The Department Health Secretariat was requested to provide a database of reported cases for the study period and 100\% of the medical records that were part of the epidemiological field investigations. The transmission route classification was established following field epidemiological investigations and following the surveillance protocol for Chagas disease in Colombia, including the epidemiological, entomological, and laboratory components (sampling).

The data were used to build a database in Microsoft Excel 365 software with sociodemographic, clinical, laboratory, and epidemiological characteristics of each of the cases (see Supplementary Table 1). The municipality constructed summary tables of acute cases from 2012 to 2020, which were supplemented with demographic data from the national statistical service (DANE) according to the report "Estimation and projection of total national, departmental and municipal population 1985-2020" (31) and the gross incidence was calculated dividing the number of cases by the projected population for each year and the lethality for Colombia and Casanare. These data were graphed with $\mathrm{R}$ studio.

To plot the number of cases of acute CD by the municipality, four quartiles were established, grouping the total of cases in the period 2012-2020, and the map was made in QGIS version 3.10.11 La Coruña. For the definition of the case, the definitions established in the SIVIGILA were used (32).

\section{Vectors and Reservoirs}

The database of triatomines collected by community surveillance in the 2012-2020 period was used. Through the community triatomine surveillance strategy, the population captures entomological material that are subsequently taken to the departmental entomology laboratory for classification and diagnosis of $T$. cruzi infection (33). From this database, the information on the main triatomine species collected that infest houses were analyzed. It was extracted by the municipality and by month of collection. Likewise, the literature about the triatomines collected in Casanare was reviewed (25).

For the climatological variables, the data of the 1981-2020 climatological average of the variables precipitation, average temperature, and relative humidity for Casanare were consulted at the Institute of Hydrology, Meteorology and Environmental Studies (IDEAM), which were analyzed for each month together 
with the average number of triatomines collected by community surveillance monthly. Lastly, reservoir information compiled from the epidemiological surveillance of acute $\mathrm{CD}$ outbreaks was included.

\section{DTUs Circulating in Casanare Department}

Finally, a literature review was carried out in the Pubmed, Google Scholar databases, and the BVS Regional Portal, with the terms, Trypanosoma cruzi, Discrete Typing Unit, DTU, Casanare or Colombia, humans; obtaining 12 articles that described the circulating DTUs by the municipality and for the department in general (see Supplementary Table 2). The information from the previous articles was extracted, discriminating it by type of DTU, species (reservoirs, vectors, and humans), and municipality. Later, it was graphed on a map using QGIS version 3.10.11 La Coruña.

\section{Statistical Analyses}

The demographic and clinical characteristics of the cases were analyzed. A database was designed in Microsoft Excel (Microsoft, Redmond, USA) that contained all the study variables, and the data analyzes were performed with Epi Info 7.2.2 and Stata (release 14, Stata Corporation, College Station, TX, USES). The descriptive and univariate analysis included demographic and clinical variables. Continuous variables were summarized using measures of central tendency and dispersion. The categorical variables were presented as frequencies and percentages. The t-student, Chi-square, or Fisher test was used to determine the significance of the difference in the bivariate analyses: comparison of signs and symptoms according to transmission route, complications according to transmission route, age groups, and differences according to outbreaks and isolated cases. For the analysis of complications, the main complications associated with acute $\mathrm{CD}$ in the literature were categorized: pericardial effusion, myocarditis, heart failure, arrhythmia, pericarditis, cardiac tamponade, meningoencephalitis, and atrial fibrillation in the group of under-aged patients (pediatric age) compared to the group over 18 years (adults) $(34,35)$. Multivariate analyzes were performed using logistic regression models. Odds Ratios $(\mathrm{OR})$ and their corresponding 95\% confidence intervals (95\% CI) were calculated for each variable. In all cases, a value of $p<0.05$ was considered statistically significant. The results are presented in tables, graphs, and maps.

\section{RESULTS}

Number of CD Cases Reported, 2012-2020

Between 2012 and 2020 in Colombia, 293 laboratory-confirmed cases of acute CD were notified to the Public Health Surveillance System (SIVIGILA). In Casanare, 232 cases were reported, 34.4\% $(n=80)$ were discarded for not meeting the case definition, $12.5 \%(29 / 232)$ children of mothers positive for T. cruzi (probable cases of congenital transmission), 8.6\% (20/232) repeated records of people who were notified in different health institutions. For the analysis of the present study, 103 cases were included: $83.5 \%(n=86)$ confirmed by laboratory, $12.6 \%(n=13)$ probable cases that shared characteristics of time, place, and person with some outbreaks, and $3.8 \%(n=4)$ confirmed by epidemiological link; the latter correspond to patients who died without laboratory confirmation, during an outbreak in which other cases were confirmed. $35.2 \%$ (103) of the acute CD cases reported in Colombia between 2012 and 2020 were from Casanare, with an average of $11( \pm 14)$ cases per year (Range 0-43). The general incidence for Casanare was 3.16 cases per 100,000 inhabitants, and the general lethality was $20 \%$, considerably exceeding the national incidence and lethality during the study period (Figure 1).

\section{Sociodemographic Characteristics}

$69.9 \%(n=72)$ of the cases occurred in males, $96.1 \%(n=$ 99) came from rural areas, $57.3 \%(n=59)$ with a contributory affiliation regime (the contributory regime is a set of rules that govern the connection of individuals and families to the General System of Social Security in Health) (36). The average age was 33 years $( \pm 15)$ (Range from 0 to 78 years) and a higher percentage of cases in the group aged $30-44$ years (see Supplementary Table 3). Cases were reported from 52.6\% ( $n$ $=10$ ) of the municipalities of Casanare; Paz de Ariporo and Maní have reported the highest number of cases. Outbreaks of presumed oral transmission occurred in Paz de Ariporo, Pore, Trinidad, San Luis de Palenque, Maní, and Yopal (Figure 2).

\section{Clinical Presentation}

$98.1 \%$ of the subjects presented febrile syndrome with a mean temperature of $38^{\circ} \mathrm{C}\left( \pm 1.3^{\circ} \mathrm{C}\right)$, sudden onset, prolonged, followed by other non-specific symptoms such as myalgias (62.1\%) and arthralgias (60.2\%). The entry signs of the parasite, such as the Romaña sign and inoculation chagoma, were rarely identified. People with acute CD consulted on day $17( \pm 9.5)$ after the onset of symptoms (Range: $0-45$ days) and, on average, had a medical consultation before diagnosis with a maximum of 6 previous consultations.

Signs/symptoms were compared according to transmission route, and there were statistically significant differences in myalgia $(p=0.012)$, abdominal pain $(p=0)$, periorbital edema $(p=0.001)$ in oral transmission. In contrast, the romaña sign occurred with a higher proportion in vector transmission with a statistically significant difference $(p=0.0007)$ (Table 1$)$. Statistically significant differences were identified between arthralgias $(p=0.012)$, abdominal pain $(p=0.00)$, periorbital edema ( $p=0.001)$ in cases of oral transmission compared with the vector route. The differences between the other signs and symptoms were not statistically significant $(p>0.05)$.

\section{Diagnosis}

Regarding the diagnostic images, $60.2 \%$ of the patients had a chest $\mathrm{X}$-ray, $54.4 \%$ an electrocardiogram, $33 \%$ an echocardiogram, and $27.2 \%$ an abdominal ultrasound; only $1.9 \%$ had Holter. The main finding on the chest X-ray was cardiomegaly, on the electrocardiogram sinus tachycardia and right bundle branch block; the echocardiogram found pericardial effusion more frequently, while the abdominal ultrasound mainly identified hepatomegaly (Table 2). 


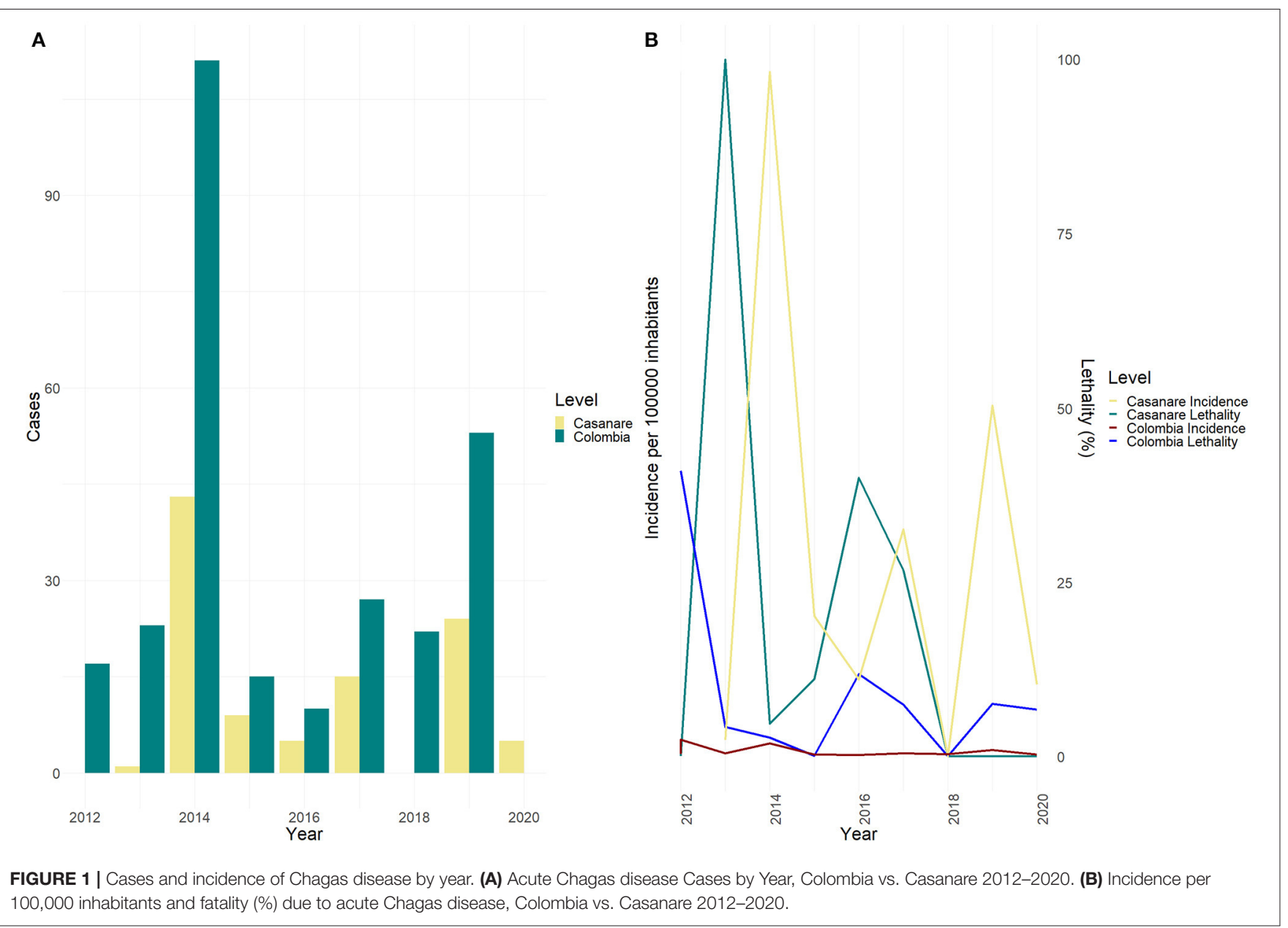

The most frequently used diagnostic tests for confirming cases of acute CD were the thick smear (56.3\%) and the micromethod (15.5\%). $23.3 \%$ of the cases had positive qPCR. The parasite load of 12 patients who tested positive by qPCR was obtained, and the median load was 21.6 (parasite equivalents $/ \mathrm{mL}$ ). $71.8 \%$ of the patients underwent serological tests, mainly ELISA or IFAT, and two seroconverted from negative to positive, classified as acute infection (see Supplementary Table 4). The main hematological alterations found were: anemia $22.3 \%(n=23)$, leukocytosis $17.4 \%(n=18)$, macroplatelets $14.5 \%(n=15)$, thrombocytopenia $13.5 \%(n=14)$ and leukopenia $7.7 \%(n=$ 8). $68.9 \%(n=71)$ of the cases had an increase in aspartate aminotransferase, $50.5 \%(n=52)$ in alanine aminotransferase and $48.5 \%(n=50)$ increased creatinine.

\section{Differential Diagnosis}

The primary differential diagnoses of admission included dengue (23.3\%), leptospirosis (6.8\%), malaria (4.9\%), and brucellosis (3.9\%). $79.6 \%$ of the cases were hospitalized, with an average hospital stay of $7( \pm 8)$ days (Range 0-35 days). There were no statistically significant differences between hospitalization according to the vector or oral route of transmission ( $p$-value:
0.758) or hospitalization differentiated between outbreaks and isolated cases ( $p$-value: 0.745 ).

\section{Complications}

$34.9 \%(n=36)$ cases presented at least one complication, mainly pericardial effusion, myocarditis, and heart failure. There were no statistically significant differences between the presence of complications and the route of transmission ( $p$-value $>0.05)$. Complications occurred more frequently in the group over 18 years old $(84.5 \%)$. The differences with the group under 18 years old were not statistically significant ( $p$-value $>0.05$ ). The highest frequency of complications occurred in cases associated with outbreaks (76.4\%) than isolated cases; these differences were not statistically significant (Table 3).

\section{Treatment}

In 90 cases $(87.3 \%)$, etiological treatment was administered, and the most frequently used drug was Benznidazole (72.8\%). The information provided for the study did not report possible adverse effects associated with the drugs or the need to change drugs. The multivariate analysis did not show associations between mortality and clinical variables (all with $p>0.05$ ). 


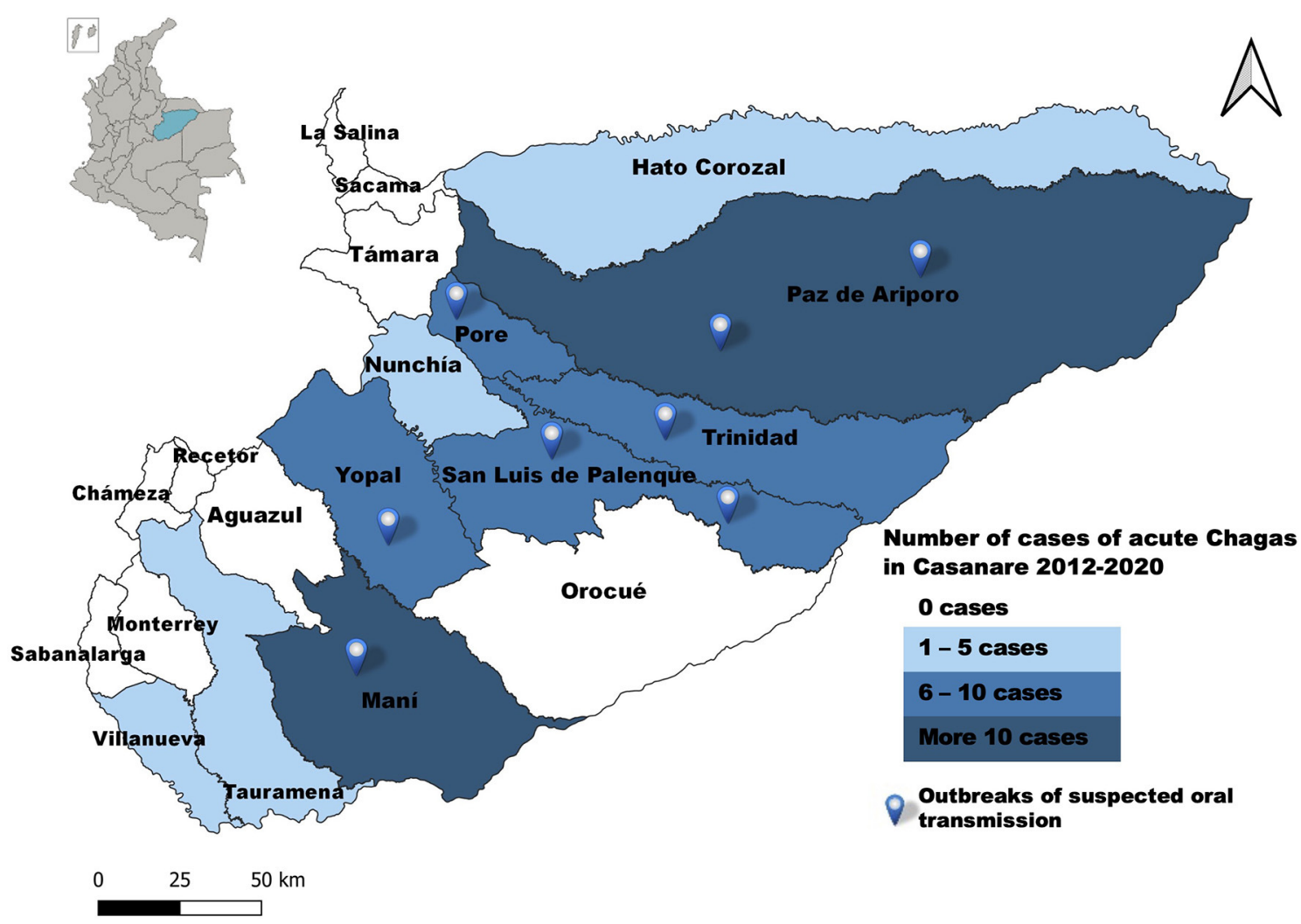

FIGURE 2 | Geographic distribution, acute Chagas disease by municipality of origin, Casanare 2012-2020.

\section{Lethality}

Ten of the cases under study had a fatal outcome; of these, $50 \%$ were men, with an average age of 26 years $( \pm 21)$, minimum age of 7 months, and a maximum of 64 years, $30 \%$ of the deceased cases were younger than 5 years. Eighty percentage of the deaths occurred in outbreaks of oral transmission. The overall fatality for the department was $10 \%$, and in some outbreaks of oral transmission, the fatality reached $50 \%$. Subjects died on average $20( \pm 21)$ days after the date of symptom onset (Range: 3-71 days). Of the total number of deaths, eight autopsies were performed; the main findings reported in the autopsies were the presence of amastigotes of T. cruzi in the myocardium and severe acute inflammatory processes; additionally, three autopsies reported encephalitis with the presence of amastigotes of $T$. cruzi. In two deaths, the previous findings were not presented, and deaths due to acute $\mathrm{CD}$ were considered by sharing characteristics of time, place, and person with confirmed cases in the framework of an outbreak. On the other hand, a case of reactivation was presented in a 64-year-old patient with HIV infection, with sudden onset of neurological symptoms, loss of sphincter control, cerebral toxoplasmosis, and T. cruzi encephalitis was diagnosed. There were no statistically significant differences between death according to the vector or oral route of transmission $(p=0.685)$.

\section{Triatomine and Mammal Species Identified Per Municipality}

According to the information obtained through the community surveillance strategy in the 2015-2020 period. Ten species of triatomines captured by the community in the intra-domicile have been identified, among which $R$. prolixus stand out in $89.5 \%$ (17/19) of the municipalities, $P$. geniculatus $73.5 \%(14 / 19)$ and T. maculata in $68.4 \%(13 / 19)$ (Figure 3).

Regarding the distribution of $T$. cruzi reservoirs in Colombia, the highest prevalence in mammals of four taxonomic orders has been reported: Didelphimorphia (35.0\%); Carnivora (17.0\%); Rodentia (6.0\%); and Chiroptera (15.0\%); identifying in Casanare positive reservoirs of the taxonomic orders: Artiodactyla, Carnívora, Chiroptera, Pilosa, and Didelphimorphia (37).

\section{Discrete Typification Units Identified in Casanare}

The detection of all DTUs described for T. cruzi throughout the epidemiological circuit has been achieved. In triatomines, TcI $\mathrm{Dom}_{\text {, }} \mathrm{TcI}_{\text {Sylvatic, }}$ and mixed TcI/TcII-VI infections have been found mostly; in reservoirs $\mathrm{TcI}_{\text {Dom }}, \mathrm{TcI}_{\text {Sylvatic }}$, and TcIII; in humans $\mathrm{TcI}_{\text {Dom }}, \mathrm{TcI}_{\text {Sylvatic }}$, and mixed TcI/TcII-VI 
TABLE 1 | Frequency of acute CD signs/symptoms, according to transmission route, Casanare 2012-2020.

\begin{tabular}{|c|c|c|c|c|c|}
\hline \multirow[t]{2}{*}{$\begin{array}{l}\text { Signs/ } \\
\text { symptoms }\end{array}$} & \multicolumn{2}{|c|}{$\begin{array}{l}\text { Oral transmission } \\
\qquad(n=85)\end{array}$} & \multicolumn{2}{|c|}{$\begin{array}{l}\text { Vector transmission } \\
\qquad(n=18)\end{array}$} & \multirow[t]{2}{*}{$P$-value } \\
\hline & requency & $\%$ & Frequency & $\%$ & \\
\hline Fever & 84 & 98.8 & 17 & 94.4 & 0.777 \\
\hline Myalgia & 58 & 68.2 & 6 & 33.3 & 0.012 \\
\hline Arthralgia & 55 & 64.7 & 7 & 38.9 & 0.077 \\
\hline Headache & 41 & 48.2 & 10 & 55.6 & 0.76 \\
\hline Tachycardia & 34 & 40.0 & 10 & 55.6 & 0.342 \\
\hline Dyspnoea & 34 & 40.0 & 5 & 27.8 & 0.481 \\
\hline $\begin{array}{l}\text { Abdominal } \\
\text { pain }\end{array}$ & 39 & 45.9 & 0 & 0.0 & 0 \\
\hline Chest pain & 22 & 25.9 & 7 & 38.9 & 0.408 \\
\hline Tachypnea & 21 & 24.7 & 4 & 22.2 & 1 \\
\hline Asthenia & 21 & 24.7 & 4 & 22.2 & 1 \\
\hline Chill & 21 & 24.7 & 3 & 16.7 & 0.554 \\
\hline Adinamia & 19 & 22.4 & 4 & 22.2 & 1 \\
\hline Facial edema & 18 & 21.2 & 4 & 22.2 & 1 \\
\hline Sickness & 18 & 21.2 & 3 & 16.7 & 1 \\
\hline Hepatomegaly & 16 & 18.8 & 4 & 22.2 & 0.747 \\
\hline $\begin{array}{l}\text { Periorbital } \\
\text { edema }\end{array}$ & 9 & 10.6 & 8 & 44.4 & 0.001 \\
\hline Vomit & 16 & 18.8 & 1 & 5.6 & 0.294 \\
\hline Cough & 15 & 17.6 & 2 & 11.1 & 0.731 \\
\hline Palpitations & 12 & 14.1 & 1 & 5.6 & 0.456 \\
\hline Diarrhea & 10 & 11.8 & 2 & 11.1 & 1 \\
\hline $\begin{array}{l}\text { Lower limb } \\
\text { edema }\end{array}$ & 9 & 10.6 & 3 & 16.7 & 0.435 \\
\hline $\begin{array}{l}\text { Romagna } \\
\text { sign }\end{array}$ & 3 & 3.5 & 6 & 33.3 & 0.0007 \\
\hline Skin rash & 7 & 8.2 & 0 & 0.0 & 0.349 \\
\hline Hepatosplenomegaly & aly 7 & 8.2 & 0 & 0.0 & 0.349 \\
\hline Bradycardia & 4 & 4.7 & 0 & 0.0 & 1 \\
\hline Splenomegaly & 4 & 4.7 & 0 & 0.0 & 1 \\
\hline Chagoma & 1 & 1.2 & 2 & 11.1 & 0.078 \\
\hline $\begin{array}{l}\text { Retroocular } \\
\text { pain }\end{array}$ & 2 & 2.4 & 1 & 5.6 & 0.441 \\
\hline
\end{tabular}

Bold values are statistically significant.

infections. In Figure 4, the geographical distribution of DTUs in the different municipalities of the department can be observed (Figure 4).

Studies carried out in triatomines have mainly identified the DTUs TcI, TcII, TcIII, TcIV, and TcVI in $R$. prolixus, $T$. maculata, P. geniculatus, and Psammolestes arthuri (27, 3841). In a study carried out in children with chronic Chagas disease from this region, DTU TcI was identified more frequently (42). In Casanare, the presence of the TcBat genotype was described for the first time in Colombia (43), TcIII was identified in the nine-banded armadillo (Dasypus novemcinctus) (44), and the presence of $\mathrm{TcI}_{\text {Sylvatic }}$ has been described in other wild species such as rats (Rattus rattus), bush rats
TABLE 2 | Main findings reported in diagnostic images, Acute CD, Casanare 2012-2020.

\begin{tabular}{|c|c|c|}
\hline $\begin{array}{l}\text { Main changes in diagnostic } \\
\text { images }\end{array}$ & Frequency & $\%$ \\
\hline \multicolumn{3}{|l|}{ X-ray } \\
\hline Abnormal & 28 & 45.2 \\
\hline Cardiomegaly & 18 & 64.3 \\
\hline Pleural effusion & 8 & 28.6 \\
\hline \multicolumn{3}{|l|}{ Electrocardiogram } \\
\hline Abnormal electrocardiogram & 29 & 51.8 \\
\hline Sinus tachycardia & 12 & 41.4 \\
\hline Right bundle branch block & 8 & 27.6 \\
\hline Nonspecific repolarization disorder & 8 & 27.6 \\
\hline AV block & 4 & 13.8 \\
\hline ST supran level & 3 & 10.3 \\
\hline Left bundle branch block & 2 & 6.9 \\
\hline Atrial fibrillation & 2 & 6.9 \\
\hline T wave inversion & 2 & 6.9 \\
\hline Sinus bradycardia & 2 & 6.9 \\
\hline Ventricular extrasystoles & 1 & 3.4 \\
\hline Echocardiogram & 24 & 85.7 \\
\hline \multicolumn{3}{|l|}{ Abnormal echocardiogram } \\
\hline Pericardial effusion & 21 & 87.5 \\
\hline Cardiac tamponade & 2 & 8.3 \\
\hline \multicolumn{3}{|l|}{ Abdominal ultrasound } \\
\hline Abnormal abdominal ultrasound & 28 & 100.0 \\
\hline Hepatomegaly & 20 & 71.4 \\
\hline Splenomegaly & 4 & 14.3 \\
\hline Free liquid in cavity & 4 & 14.3 \\
\hline
\end{tabular}

(Proechimys sp.), howler monkeys (Alouatta sp.) and anteater (Tamandua tetradactyla) (45).

\section{Weather Conditions}

According to the weather conditions reported by IDEAM, Casanare's average rainfall in January was $20.2 \mathrm{~mm}$ and starting this month, it begins to increase, being $273.1 \mathrm{~mm}$ in April, May with $387 \mathrm{~mm}$ and the maximum average in June with $398.1 \mathrm{~mm}$. When comparing with the results of the community surveillance of triatomines, an increase in the frequency of collection of vectors was found inside the houses in April and May, which coincides with the more significant precipitation and the greater number of cases of acute CD reported (Figure 5). In the acute orally transmitted CD outbreaks in 2014, 2016, and 2020, a decrease in precipitation was observed below average. In the 2014 outbreak, which has been the largest to date in Colombia, these outbreaks were related to reservoirs, mainly Didelphis marsupialis, which due to climatic conditions, approached human dwellings in search of food and water $(21,46,47)$.

\section{DISCUSSION}

In this study, some epidemiological patterns can be discerned. However, it has been described in the literature that most patients 


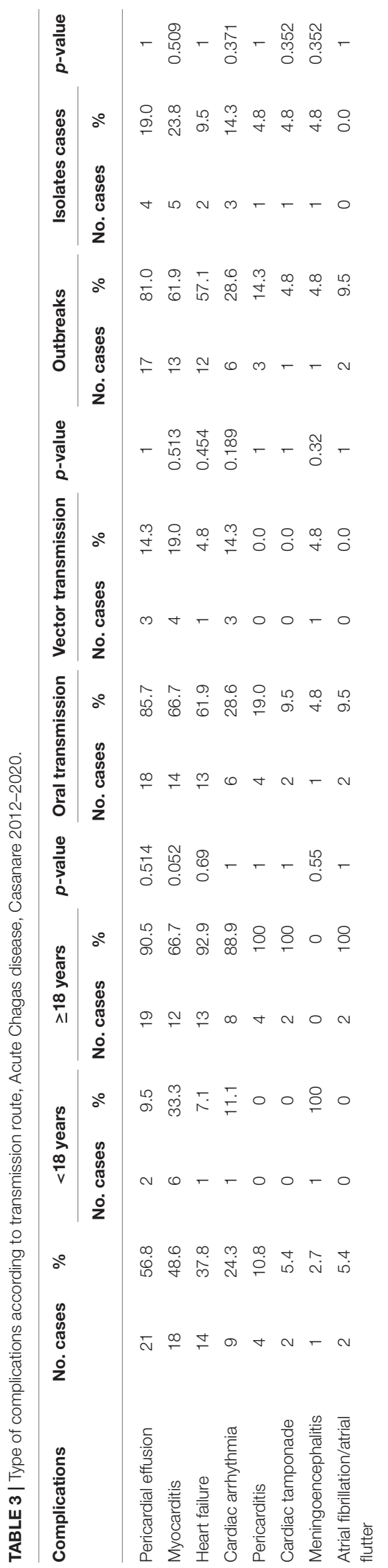

with acute manifestations of $\mathrm{CD}$ are children (48). In the present investigation, the highest percentage of cases occurred in young adults (between 30 and 34 years old), a behavior similar to that reported in Brazil in the most extensive series of cases documented to date; however, in Casanare, the most significant affectation occurred in males, which could be related to economic activity, in contrast with Brazil (49) (Supplementary Table 3). The most frequent clinical presentation was a febrile syndrome, with sudden and prolonged onset, mainly accompanied by myalgias, arthralgias, and headache (Table 1). Fever remains the main symptom, similar to that found in other regions of Colombia $(50,51)$ and even in countries like Brazil and Venezuela (52-54).

In the study period, the incubation average was 17 days ( \pm 9.5$)$, higher than that reported in Mérida-Venezuela, where symptoms are described in an average of 12 days \pm 3 (55). This finding has clinical and epidemiological relevance since it reaffirms the importance and need to suspect this pathology in people with prolonged febrile syndromes. In whom parasitological tests should be performed, and timely treatments can be established, the subjects under study had up to 6 medical consultations before diagnosis. It is noteworthy that, even though Casanare is considered an endemic region for CD, 23.3\% of the study subjects had dengue as a diagnosis of admission, which delays treatment and leads to the onset of possible complications. This situation has also been described in other series of cases in Colombia $(56,57)$. Even in other countries where the diagnosis of acute $\mathrm{CD}$ is made post-mortem (58) by identifying amastigotes of $T$. cruzi in the myocardium. Infectious diseases such as malaria, leptospirosis, brucellosis, rickettsiosis, and histoplasmosis, among others, are part of the differential admission diagnoses identified in our series of cases and other countries (59). This reinforces the need to train medical personnel in endemic regions for a timely diagnosis of acute $\mathrm{CD}$.

Regarding the signs such as the Romaña sign and inoculation chagoma, these were rarely identified in the series of cases analyzed ( 9 patients with Romaña sign and 3 with chagoma) and the described in Brazil where out of 233 cases, 6 presented front door signs (49). In contrast to the descriptions made by Dias in a series of cases from Brazil and Argentina where the frequency of these signs was between 12.5 and 95.5\% (60). In a study carried out in Barinas-Venezuela, signs of entry of the parasite were found in $45.8 \%$ (27/59) of the cases (61). In general, gastrointestinal symptoms such as abdominal pain, nausea, vomiting, and diarrhea were found more frequently in cases associated with oral transmission in the present study, similar to what was identified in other outbreaks of oral transmission reported both in Colombia and in South America (43-45). Hepatomegaly and splenomegaly infrequently occurred, 19.5 and $3 \%$, respectively, with an average age of 25 years, unlike the reports in Bambuí-Brazil where they were reported in 66 and 31\%, respectively, being marked in children from zero to 2 years, in whom it was considered a marker of poor prognosis (60). In the analysis carried out in this study, $20 \%$ of the subjects with hepatomegaly died, which could also be considered an indicator of poor prognosis 

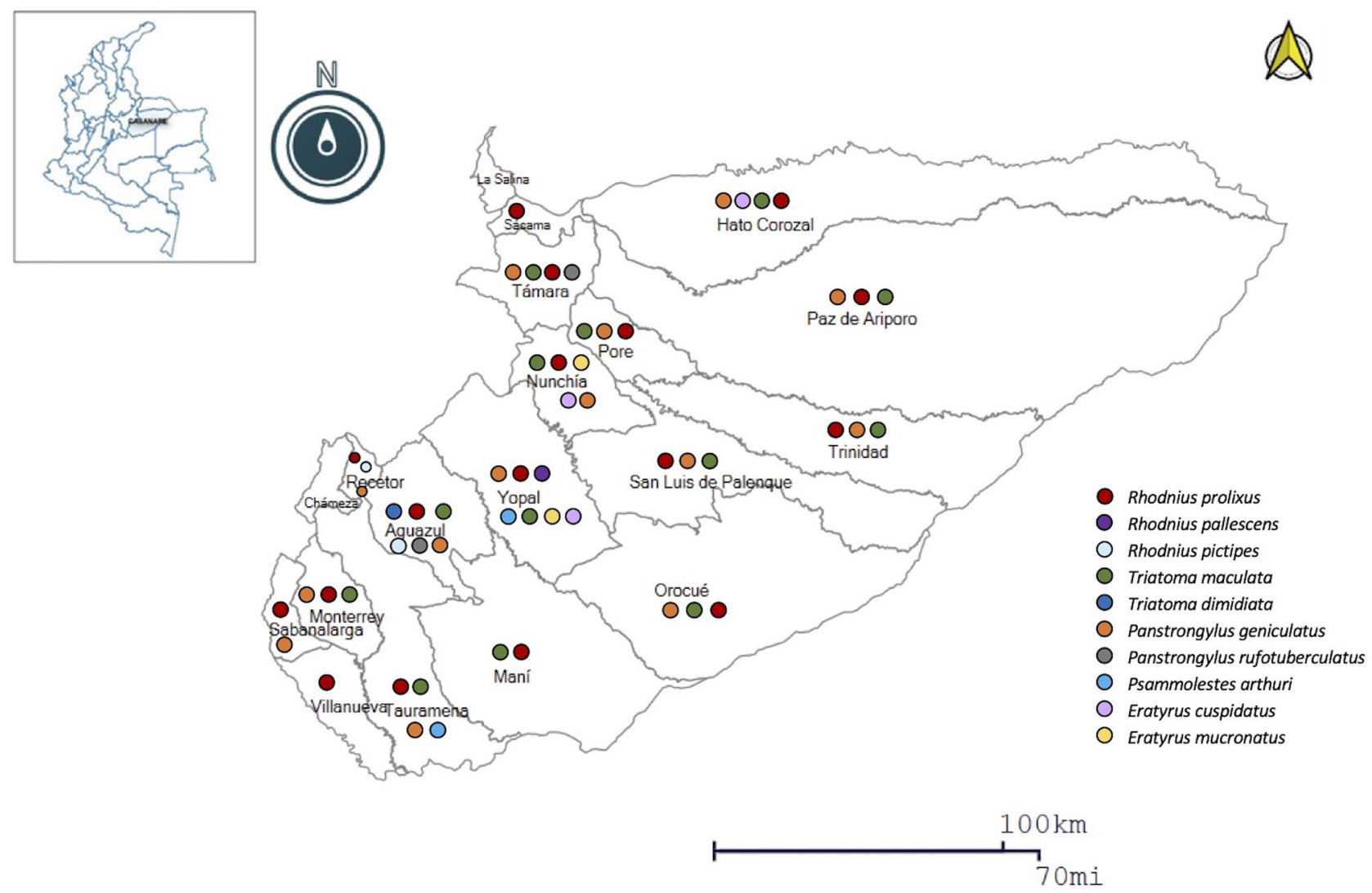

FIGURE 3 | Geographic distribution of the main triatomine species in Casanare.

that leads to strengthening the clinical follow-up of acute CD cases.

The frequency of electrocardiographic anomalies in the present investigation was $51.8 \%$, and the main alterations were sinus tachycardia, right bundle branch block, and non-specific repolarization disorder (Table 2), different from that reported by Pinto et al. in Brazil, where in 233 cases studied, $51.1 \%$ had EKG alterations with a predominance of diffuse alterations in ventricular repolarization, low voltage of the QRS fields and sinus tachycardia (49). In the study of an outbreak due to oral transmission in a school in Caracas-Venezuela, 61 patients were studied; in those under 18 years of age (48), T wave anomalies and ST abnormalities were more frequent and supraventricular arrhythmias predominated in the adults (62). This could be explained by the difference in the virulence of the $T$. cruzi strains and, additionally, by the parasite-host interaction that can produce different responses from the immune system and other organs (63).

$34.9 \%$ of the subjects had at least one complication in the present series of cases, mainly pericardial effusion, myocarditis, and heart failure. Different results from those described in Santander-Colombia, where 12 cases were studied, $66.6 \%$ had heart failure as the main complication, followed by pericardial effusion with $41.6 \%$ (50). Some authors suggest that in cases of oral transmission, more significant complications could occur in adults than children since the former would consume a greater quantity of food containing a more significant number of infective metacyclic of T. cruzi $(55,64)$. In the present study, although complications occurred more frequently in those over 18 years of age, the difference with those under 18 was not statistically significant. Likewise, although it was found that the highest frequency of complications occurred in cases associated with outbreaks in which the oral transmission hypothesis was raised, the difference was not significant compared to vector transmission (Table 3). The results of this study corroborate the importance of timely detection and treatment of people in the acute phase of the disease and long-term follow-up of patients undergoing treatment. The need for other studies complemented with molecular epidemiology is raised to generate knowledge that allows the control of the disease, considering the epidemiological, ecological, and cultural characteristics of regions such as Casanare.

This study shows that mortality was higher in males, in the young adult population (26 years \pm 21 ), a situation that can be related to work activity; $30 \%$ of subjects who died were from the group under 5 years old, findings different from those described in the series of cases in Brazil between 1988 and 2005 where fatality was more frequent in adults 


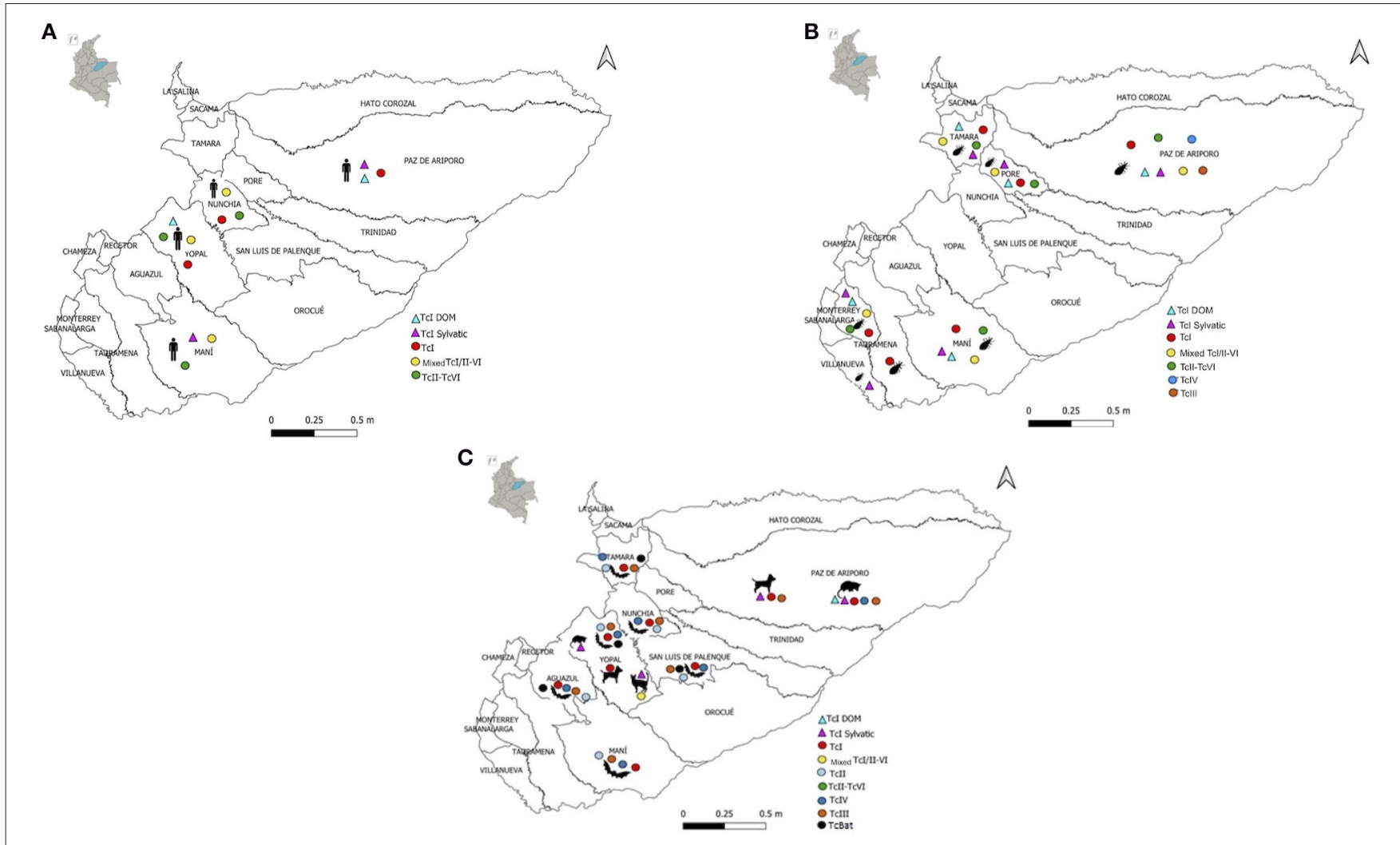

FIGURE 4 | Geographic distribution of DTUs identified in different Casanare species; (A) Distribution of DTUs in humans (Homo sapiens); (B) Distribution of DTUs in triatomines; (C) Distribution of DTUs in reservoirs (Canis familiaris, Didelphis marsupialis, Felis catus).

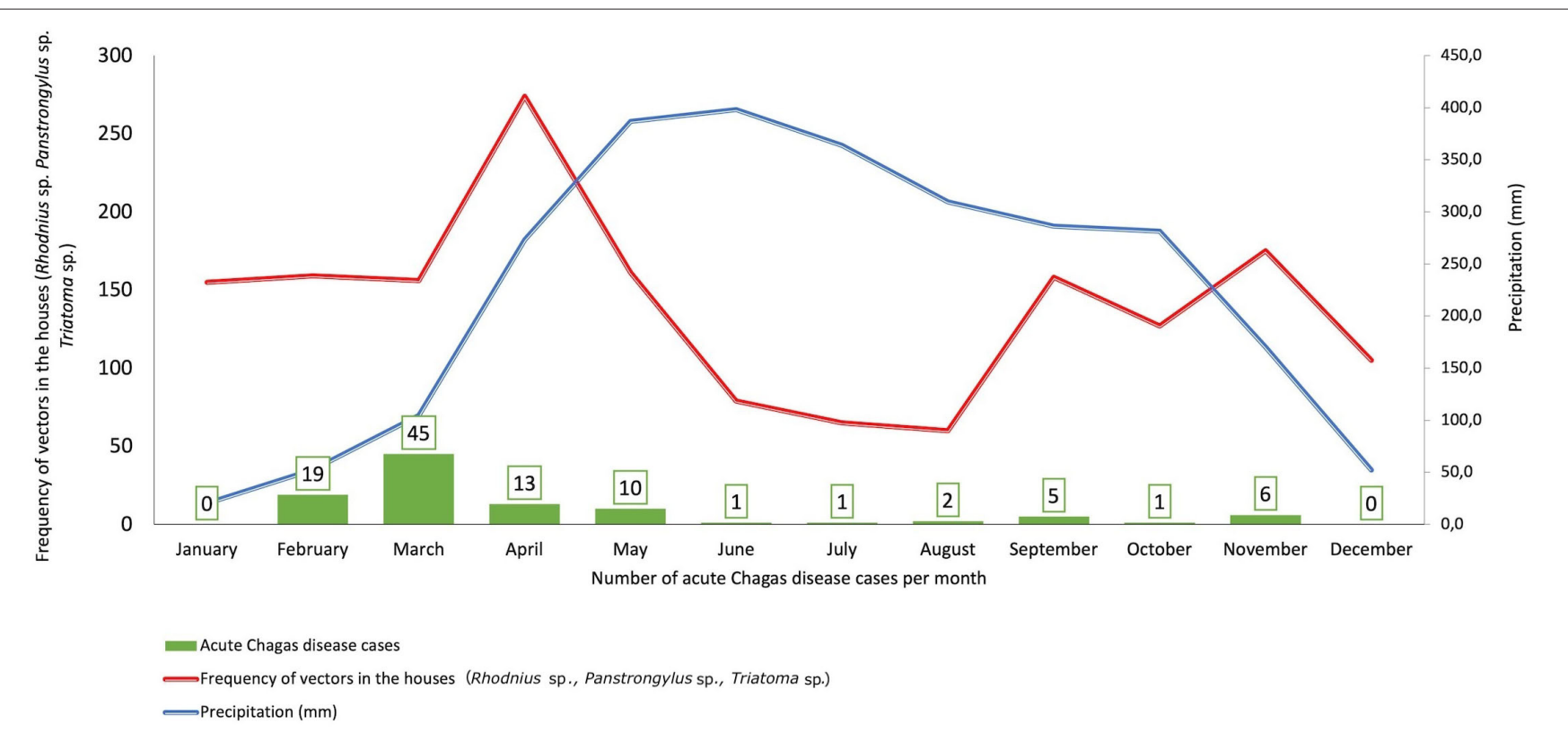

FIGURE 5 | Climatic conditions, frequency of vectors by community surveillance vs. Number of Acute Chagas disease cases, Casanare $2012-2020$. 
over 50 years old (49). However, both results shown in this study and those described in the region's countries reaffirm that there may be a greater risk of fatality in extreme ages. On average, the subjects died 20 days after symptoms onset $( \pm 21)$, and the main finding in the autopsies was the presence of amastigotes of $T$. cruzi in the myocardium, also reported in subjects who have died in Venezuela and Brazil (64-66). It is noteworthy that one of the cases analyzed corresponded to reactivation in an immunosuppressed patient with HIV, who presented neurological symptoms with a diagnosis of $T$. cruzi encephalitis. In this regard, the literature mentions that neurological manifestations in $75 \%$ accompany reactivations in patients with HIV-AIDS to $90 \%$ of cases $(67,68)$. In this context, Chagas disease control programs must include HIV screening in patients with chronic Chagas disease and vice versa, especially in endemic areas, where reactivation of Chagas disease should be considered in the differential diagnosis of meningoencephalitis among HIV-infected patients $(69,70)$.

The fatality due to acute Chagas disease was higher in Casanare than in Colombia in the study period. Several reasons could explain this: first, most of the cases analyzed were of oral transmission, which has been associated with higher fatality (48); likewise, in Casanare, a greater prevalence of sylvatic TcI DTU has been found, the genotype most likely associated with the oral transmission which has been identified in vectors, reservoirs, and humans, reaffirming the role of this DTU in the oral transmission of the disease (21), since the infection in humans is accidental, given the intrusion of the parasite into the domestic environment from the sylvatic cycle, as previously described in other outbreaks in Colombia (71), Venezuela, French Guyana and Brazil $(17,72)$. It is also important to bear in mind that, in remote regions of Colombia such as Casanare, timely access to the health system is limited. In Casanare, $65 \%$ of the health services with hospitalization are in the capital of the department with a proportion of 12 beds per 10,000 inhabitants (29), and $84.2 \%$ of the municipalities only have institutions that provide health services of the first level of care where the medical staff and supplies are insufficient, which could be related to the delays in the timely identification of patients with Chagas disease and increases the risk of complications.

On the other hand, the most frequently used diagnostic methods to demonstrate parasitemia in the study subjects were thick blood smear and concentration methods such as the micromethod with the positivity of 56.3 and $15.5 \%$, respectively (Supplementary Table 4). In a study carried out in Venezuela, positive thick smear percentages of $34 \%$ were found, and xenodiagnosis was the second most frequent method, with a positivity of $61 \%$ (49). The $23.3 \%$ of the cases under study were diagnosed with qPCR; however, this test is not part of the diagnostic algorithm validated in Colombia, and although it has shown high sensitivity, it is usually available only in reference or research laboratories $(59,73)$. This demonstrates the need to perform qPCR at least in outbreak studies in Colombia, strengthening epidemiological surveillance, especially in endemic regions.

Regarding the genetic diversity of T. cruzi, in Casanare, as in Colombia, TcI predominates in domestic and sylvatic cycles of transmission, and in patients in the chronic phase, coinfection of TcI-TcII, TcI-TcIV, as well as the unique presence of TcII (74). A study conducted in children with chronic Chagas disease from Casanare identified the TcII-TcVI genotypes (42). On the other hand, in Casanare, ten species have been identified, of which $R$. prolixus stands out in $89.5 \%$ of the municipalities, and the TcITcVI DTUs have been identified in R. prolixus, T. maculata, $P$. geniculatus, and Ps. arthuri captured in the department $(27,38-$ 40) (Figures 3, 4).

The appearance of acute CD cases in Casanare is due to human interaction with the domestic and sylvatic cycles circulating in the department, thus generating outbreaks and isolated cases. In the domestic cycle, the interaction with primary vectors such as $R$. prolixus has been related to climatic factors such as precipitation $(26,27)$, finding that its frequency in homes increases in times of low rainfall and decreases in the months of higher precipitation (Figure 5). Likewise, the continuous contact of humans mainly in rural areas with reservoirs such as Didelphis marsupialis favors the interaction with DTUs of the domestic cycle and could explain the presence of some acute and chronic cases. These climatic conditions could favor the intrusion of secondary vectors in the houses, favoring the appearance of oral outbreaks and isolated acute cases such as those observed by $P$. geniculatus in which sylvatic cycle DTUs involved in the outbreaks are observed, and that typically are related to greater clinical severity and higher parasitemia in both human and animal models.

On the other hand, economic activities developed in the department such as oil exploitation or extensive crops favor human contact with wild transmission cycles, to the point of generating outbreaks of oral transmission, as occurred in the municipality of Paz de Ariporo in 2014, where the responsible DTU was TcI of sylvatic origin through the close contact of wild reservoirs (21). Recently, Casanare has ventured into the agro-industrial cultivation of oil palm (Elaeis guineensis) as a potential economic activity in the region, which also favors the invasion of humans in wild cycles and contact with reservoirs and triatomines present in the palms. These economic activities of great importance for the development of the department explain why in our study, the highest frequency of cases occurred in males in people of productive age. Ecologically, the department has a wide distribution of native Attalea butyracea palms in which an abundant presence of triatomines has been found, mainly $R$. prolixus (24), challenging the control of the disease.

It is mainly those accidental events (intrusions of vectors and reservoirs in homes and/or human intrusions in sylvatic environments), which are responsible for the appearance of acute cases and outbreaks; coupled with climatic conditions that favor interactions between transmission cycles and the region's ecological conditions, which make Casanare an endemic department for acute Chagas disease. These findings suggest the importance of designing strategies to control triatomine intrusion into homes and strengthening preventive measures in the community and the capacities of medical and paramedical personnel from health institutions, especially during the first quarter of the year. 


\section{CONCLUSIONS}

Casanare, an endemic department for $\mathrm{CD}$, not only has the highest prevalence of the disease in the country but has also reported the highest number of cases in the acute phase in the period 2012-2020, mainly affecting young adult men in the populated centers. The clinical presentation of the disease is polysymptomatic, almost always accompanied by a prolonged febrile syndrome, with a good prognosis when a timely diagnosis is made. It is necessary to strengthen the importance of immediate diagnosis and treatment of acute CD cases and longterm follow-up of patients. Considering the epidemiological behavior of the disease, it is necessary to establish individual and collective intersectoral public health policies adapted to local settings to achieve the timely detection of acute cases and thus prevent the chronic phase and possible complications.

\section{DATA AVAILABILITY STATEMENT}

The data analyzed in this study is subject to the following licenses/restrictions: the data sets generated analyzed during the current study are not publicly available because they contain sensitive data from the analyzed medical records, however, they are available from the corresponding author upon reasonable request. The information related to the manual collection of vectors is not available for publication, considering that it is part of the community surveillance database of the public health surveillance system of the Health secretariat of Casanare, this information can be requested directly in this institution. Information related to DTUs in Casanare is included in Supplementary Table 2. Data related to IDEAM are in the public domain and can be found at http://atlas.ideam.gov.co/ visorAtlasClimatologico.html. Requests to access these datasets should be directed to juand.ramirez@urosario.edu.co.

\section{REFERENCES}

1. Chatelain E. Chagas disease research and development: is there light at the end of the tunnel? Comput Struct Biotechnol J. (2017) 15:98103. doi: 10.1016/j.csbj.2016.12.002

2. World Health Organization. Chagas disease in Latin America: an epidemiological update based on 2010 estimates. Vol. 90. In: Weekly Epidemiological Record. Geneva (2015). Available online at: https://www.who. int/wer/2015/wer9006.pdf?ua=1 (accessed February 20, 2021).

3. Macedo AM, Segatto M. Implications of trypanosoma cruzi intraspecific diversity in the pathogenesis of Chagas disease. In: American Trypanosomiasis. Elsevier (2010). p. 489-522. Available online at: https://linkinghub.elsevier. com/retrieve/pii/B9780123848765000204 (accessed February 20, 2021).

4. Zingales B. Trypanosoma cruzi genetic diversity: something new for something known about Chagas disease manifestations, serodiagnosis, and drug sensitivity. Acta Trop. (2018) 184:3852. doi: 10.1016/j.actatropica.2017.09.017

5. Pinto CM, Ocaña-Mayorga S, Tapia EE, Lobos SE, Zurita AP, Aguirre-Villacís F, et al. Bats, trypanosomes, and triatomines in ecuador: new insights into the diversity, transmission, and origins of Trypanosoma cruzi and Chagas disease. PLoS ONE. (2015) 10:e139999. doi: 10.1371/journal.pone.0139999

6. León CM, Hernández C, Montilla M, Ramírez JD. Retrospective distribution of Trypanosoma cruzi I genotypes in Colombia. Mem Inst Oswaldo Cruz. (2015) 110:387-93. doi: 10.1590/0074-02760140402

\section{ETHICS STATEMENT}

The studies involving human participants were reviewed and approved by the ethics committee of Universidad del Rosario Act number 426 from July 30th, 2020. Written informed consent for participation was not required for this study in accordance with the national legislation and the institutional requirements.

\section{AUTHOR CONTRIBUTIONS}

CR-A and AP-G: obtaining information, analysis, writing, and revision and editing of the manuscript. MO: analysis of results and review of methodology of the manuscript. FT-T: information gathering and technical review of the manuscript. LZ-D: technical review of the manuscript. $\mathrm{CH}$ : analysis of results DTU Casanare and review of manuscript writing. JR: thematic and methodological review of the manuscript. All authors read and approved the final manuscript.

\section{ACKNOWLEDGMENTS}

The authors thank the Secretary of Health of Casanare, the Vector-Borne Diseases program for the information provided. To Dr. Giovanny Herrera for the graphs in R. This is an investigation carried out to obtain a Master's degree in Public Health from the Universidad del Rosario, Bogotá, Colombia.

\section{SUPPLEMENTARY MATERIAL}

The Supplementary Material for this article can be found online at: https://www.frontiersin.org/articles/10.3389/fmed. 2021.681635/full\#supplementary-material

7. Jiménez P, Jaimes J, Poveda C, Ramírez JD. A systematic review of the Trypanosoma cruzi genetic heterogeneity, host immune response and genetic factors as plausible drivers of chronic CHAGASic cardiomyopathy. Parasitology. (2019) 146:269-83. doi: 10.1017/S0031182018001506

8. Bern C. Chagas' disease. N Engl J Med. (2015) 373:45666. doi: 10.1056/NEJMra1410150

9. Echeverria LE, Morillo CA. American trypanosomiasis (Chagas disease). Infect Dis Clin North Am. (2019) 33:119-34. doi: 10.1016/j.idc.2018.10.015

10. Malik LH, Singh GD, Amsterdam EA. The epidemiology, clinical manifestations, and management of Chagas heart disease. Clin Cardiol. (2015) 38:565-9. doi: 10.1002/clc.22421

11. Prata A. Clinical and epidemiological aspects of Chagas disease. Lancet Infect Dis. (2001) 1:92-100. doi: 10.1016/S1473-3099(01)00065-2

12. Mady C, Nacruth R. Natural history of chronic Chagas' heart disease: prognosis factors. Sáo Paulo Med J. (1995) 113:7916. doi: 10.1590/S1516-31801995000200009

13. Montoya A, Rincón RA, Nieves PA, Ibañez HO, Plata G. Manifestaciones digestivas de la enfermedad de Chagas. In: Fernando R, Vanegas DI, Cabrales MF, editors. Enfermedad de Chagas. Sociedad Colombiana de Cardiología. (2007). p. 43-6. Available online at: http://scc.org.co/wp-content/uploads/ 2012/08/chagas_completo.pdf (accessed February 20, 2021).

14. Filigheddu MT, Górgolas M, Ramos JM. Enfermedad de Chagas de transmisión oral. Med Clin. (2017) 148:12531. doi: $10.1016 /$ j.medcli.2016.10.038 
15. Bruneto EG, Fernandes-Silva MM, Toledo-Cornell C, Martins S, Ferreira JMB, Corrêa VR, et al. Case-fatality from orally-transmitted acute Chagas disease: a systematic review and meta-analysis. Clin Infect Dis. (2020) 72:1084-92. doi: 10.1093/cid/ciaal148

16. Organización Panamericana de la Salud. Control, interrupción de la transmisión y eliminación de la enfermedad de Chagas como problema de salud pública. Guía de evaluación, verificación y validación. Washington, D.C (2019). Available online at: https://iris.paho.org/bitstream/handle/10665.2/ 51648/9789275121528- spa.pdf?sequence $=7$ \&isAllowed $=y$ (accessed February 20, 2021).

17. Rueda K, Trujillo JE, Carranza JC, Vallejo GA. Transmisión oral de Trypanosoma cruzi: un nuevo escenario epidemiológico de la enfermedad de Chagas en Colombia y otros países suramericanos. Biomédica. (2014) 34:631-41. doi: 10.7705/biomedica.v34i4.2204

18. Olivera MJ, Fory JA, Porras JF, Buitrago G. Prevalence of Chagas disease in Colombia: a systematic review and meta-analysis. PLoS ONE. (2019) 14:1-18. doi: 10.1371/journal.pone.0210156

19. Instituto Nacional de Salud. Boletín epidemiológico semana 33 de 2019. Vol. 33, Semanal, Boletín Epidemiológico. Bogotá-Colombia: Institiuto Nacional de Salud-Colombia (2019). p. 4. Available online at: https://www.ins.gov.co/P aginas/PageNotFoundError.aspx?requestUrl=https://www.ins.gov.co/buscad or-\%20eventos/BoletinEpidemiologico/2019\%20Bolet\%C3\%ADn\%20epidem iol\%C3\%B3gico\%20semana\%2033.pdf (accessed February 20, 2021).

20. Zuleta-Dueñas LP, López-Quiroga ÁJ, Torres-Torres F, Castañeda-Porras O, Castañeda-Porras O. Posible transmisión oral de la enfermedad de Chagas en trabajadores del sector de los hidrocarburos en Casanare, Colombia. Biomédica. (2014) 37:218-32. doi: 10.7705/biomedica.v37i3.3153

21. Hernández C, Vera MJ, Cucunubá Z, Flórez C, Cantillo O, Buitrago LS, et al. High-resolution molecular typing of Trypanosoma cruzi in 2 large outbreaks of acute Chagas disease in Colombia. J Infect Dis. (2016) 214:12525. doi: 10.1093/infdis/jiw360

22. Castillo-Riquelme M, Guhl F, Turriago B, Pinto N, Rosas F, Martínez MF, et al. The costs of preventing and treating Chagas disease in Colombia. PLoS Negl Trop Dis. (2008) 2:e336. doi: 10.1371/journal.pntd.0000336

23. Bartsch SM, Avelis CM, Asti L, Hertenstein DL, Ndeffo-Mbah M, Galvani A, et al. The economic value of identifying and treating Chagas disease patients earlier and the impact on Trypanosoma cruzi transmission. PLoS Negl Trop Dis. (2018) 12:e0006809. doi: 10.1371/journal.pntd.0006809

24. Guhl F, Aguilera G, Pinto N, Vergara D. Actualización de la distribución geográfica y ecoepidemiología de la fauna de triatominos (Reduviidae: Triatominae) en Colombia. Biomédica. (2007) 27:143. doi: 10.7705/biomedica.v27i1.258

25. Zuleta-Dueñas LP. Capítulo 6. Vigilancia de triatominae (hemiptera: reduviidae) en Casanare. In: Parra-Henao GJ, Flórez Martínez M, AnguloSilva VM, editors. Vigilancia de Triatominae (Hemiptera: Reduviidae) en Colombia. 1era Edici. Bogotá: Sic Editorial Ltda. (2015). p. 43-52. Available online at: https://www.ucc.edu.co/sitios/catalogo/SiteAssets/Lists/saladepre nsa/poranyomes/LIBROVIGILANCIATRIATOMINAEENCOLOMBIA.pdf (accessed February 20, 2021).

26. Urbano P, Hincapié E, Angulo VM, Esteban L, Núñez-Avellaneda LA. Variación poblacional de Rhodnius prolixus (Reduviidae: Triatominae) en Attalea butyracea (Arecaceae) en la Orinoquia colombiana. Rev Colomb Entomol. (2018) 44:211-6. doi: 10.25100/socolen.v44i2.7315

27. Rincón-Galvis HJ, Urbano P, Hernández C, Ramírez JD. Temporal variation of the presence of Rhodnius prolixus (Hemiptera: Reduviidae) into rural dwellings in the Department of Casanare, Eastern Colombia. J Med Entomol. (2020) 57:173-80. doi: 10.1093/jme/tjz162

28. Ministerio de Salud y Protección Social. Decreto 780 de 2016. Decreto Único Reglamentario del Sector Salud y Protección Social. Colombia (2016). Available online at: https://www.minsalud.gov.co/Normatividad_ Nuevo/Decreto0780de2016.pdf (accessed February 20, 2021).

29. Secretaría de Salud de Casanare. Análisis de Situación de Salud con el modelo de los Determinantes Sociales De Salud - Casanare. Yopal, Casanare (2019). p. 1-186. Available online at: https://www.casanare.gov.co/Dependencias/Salud/ SaladePrensa/Paginas/Analisis-de-Situación-en-Salud-con-el-Modelo-delos-Determinantes-Sociales-en-Salud.aspx (accessed February 20, 2021).

30. Angulo VM, Esteban L, Luna KP. Attalea butyracea próximas a las viviendas como posible fuente de infestación domiciliaria por Rhodnius prolixus
(Hemiptera: Reduviidae) en los Llanos Orientales de Colombia. Biomédica. (2012) 32:277-85. doi: 10.7705/biomedica.v32i2.430

31. Departamento Administrativo Nacional de Estadística. Estimaciones de población 1985 - 2005 y proyecciones de población 2005 - 2020 total municipal por área. Bogotá (2009). Available online at: https://www.dane.gov.co/files/ investigaciones/poblacion/proyepobla06_20/7Proyecciones_poblacion.pdf (accessed February 20, 2021).

32. Instituto Nacional de Salud. Protocolo de vigilancia en salud pública. Chagas. (2017). Available online at: https://www.ins.gov.co/buscador-eventos/ Lineamientos/PROChagas_.pdf (accessed February 20, 2021).

33. Ministerio de la Protección Social. G para la vigilancia entomológica y control de la transmisión de la enfermedad de Chagas. Bogotá-Colombia: Ministerio de la Protección Social (2017).

34. Ministerio de Salud y Protección Social. Ciclo de Vida. Available online at: https://www.minsalud.gov.co/proteccionsocial/Paginas/cicloVida.aspx (accessed February 20, 2021).

35. Gobierno de Colombia, Instituto Colombiano de Bienestar Familiar. Política nacional de infancia y adolescencia 2018-2030. (2018). Available online at: https://www.icbf.gov.co/sites/default/files/politica_nacional_de_infancia_ Y_adolescencia.pdf (accessed February 20, 2021).

36. Ministerio de Salud y Protección Social. Regimen Contributivo. Available online at: https://www.minsalud.gov.co/proteccionsocial/ Regimencontributivo/Paginas/regimen-contributivo.aspx (accessed February 20, 2021).

37. Rodríguez-Monguí E, Cantillo-Barraza O, Prieto-Alvarado FE, Cucunubá $\mathrm{ZM}$. Heterogeneity of Trypanosoma cruzi infection rates in vectors and animal reservoirs in Colombia: a systematic review and meta-analysis. Parasit Vectors. (2019) 12:308. doi: 10.1186/s13071-019-3541-5

38. Velásquez-Ortiz N, Hernández C, Herrera G, Cruz-Saavedra L, Higuera A, Arias-Giraldo LM, et al. Trypanosoma cruzi infection, discrete typing units and feeding sources among Psammolestes arthuri (Reduviidae: Triatominae) collected in eastern Colombia. Parasit Vectors. (2019) 12:157. doi: 10.1186/s13071-019-3422-y

39. Erazo D, Gottdenker NL, González C, Guhl F, Cuellar M, Kieran TJ, et al. Generalist host species drive Trypanosoma cruzi vector infection in oil palm plantations in the Orinoco region, Colombia. Parasit Vectors. (2019) 12:274. doi: 10.1186/s13071-019-3519-3

40. Jácome-Pinilla D, Hincapie-Peñaloza E, Ortiz MI, Ramírez JD, Guhl F, Molina J. Risks associated with dispersive nocturnal flights of sylvatic Triatominae to artificial lights in a model house in the northeastern plains of Colombia. Parasit Vectors. (2015) 8:600. doi: 10.1186/s13071-015-1209-3

41. Hernández C, Salazar C, Brochero H, Teherán A, Buitrago LS, Vera $M$, et al. Untangling the transmission dynamics of primary and secondary vectors of Trypanosoma cruzi in Colombia: parasite infection, feeding sources and discrete typing units. Parasit Vectors. (2016) 9:620. doi: 10.1186/s13071-016-1907-5

42. Bianchi F, Cucunubá Z, Guhl F, González NL, Freilij H, Nicholls RS, et al. Follow-up of an asymptomatic Chagas disease population of children after treatment with nifurtimox (Lampit) in a sylvatic endemic transmission area of Colombia. PLoS Negl Trop Dis. (2015) 9:e0003465. doi: 10.1371/journal.pntd.0003465

43. Ramírez JD, Tapia-Calle G, Muñoz-Cruz G, Poveda C, Rendón LM, Hincapié E, et al. Trypanosome species in neo-tropical bats: biological, evolutionary and epidemiological implications. Infect Genet Evol. (2014) 22:250-6. doi: 10.1016/j.meegid.2013.06.022

44. Messenger LA, Ramirez JD, Llewellyn MS, Guhl F, Miles MA. Importation of hybrid human-associated Trypanosoma cruzi strains of Southern South American Origin, Colombia. Emerg Infect Dis. (2016) 22:14525. doi: 10.3201/eid2208.150786

45. Ramírez JD, Duque MC, Guhl F. Phylogenetic reconstruction based on Cytochrome b (Cytb) gene sequences reveals distinct genotypes within Colombian Trypanosoma cruzi I populations. Acta Trop. (2011) 119:615. doi: 10.1016/j.actatropica.2011.04.009

46. Roque ALR, D'Andrea PS, Jansen AM, Duarte ACM, Xavier SCC, da Rocha MG. Trypanosoma cruzi transmission cycle among wild and domestic mammals in three areas of orally transmitted Chagas disease outbreaks. Am J Trop Med Hyg. (2008) 79:742-9. doi: 10.4269/ajtmh.2008. 79.742 
47. Shikanai-Yasuda MA, Carvalho NB. Oral transmission of Chagas disease. Clin Infect Dis. (2012) 54:845-52. doi: 10.1093/cid/cir956

48. Andrade D V, Gollob KJ, Dutra WO. Acute Chagas disease: new global challenges for an old neglected disease. PLoS Negl Trop Dis. (2014) 8:e3010. doi: 10.1371/journal.pntd.0003010

49. Pinto AYDN, Valente SA, Valente VDC, Ferreira Junior AG, Coura JR. Fase aguda da doença de Chagas na Amazônia brasileira: estudo de 233 casos do Pará, Amapá e Maranhão observados entre 1988 e 2005. Rev Soc Bras Med Trop. (2008) 41:602-14. doi: 10.1590/S0037-86822008000600011

50. Díaz ML, Leal S, Mantilla JC, Molina-Berríos A, López-Muñoz R, Solari A, et al. Acute Chagas outbreaks: molecular and biological features of Trypanosoma cruzi isolates, and clinical aspects of acute cases in Santander, Colombia. Parasit Vectors. (2015) 8:608. doi: 10.1186/s13071-015-1218-2

51. Ríos JF, Arboleda M, Montoya AN, Alarcón EP, Parra-Henao GJ. Probable brote de transmisión oral de enfermedad de Chagas en Turbo, Antioquia. Biomédica. (2011) 31:185. doi: 10.7705/biomedica.v31i2.302

52. de Barros Moreira Beltrão H, de Paula Cerroni M, de Freitas DRC, das Neves Pinto AY, da Costa Valente V, Valente SA, et al. Investigation of two outbreaks of suspected oral transmission of acute Chagas disease in the Amazon region, Pará State, Brazil, in 2007. Trop Doct. (2009) 39:2312. doi: 10.1258/td.2009.090035

53. Bastos CJC, Aras R, Mota G, Reis F, Dias JP, Jesus RS de, et al. Clinical outcomes of thirteen patients with acute Chagas disease acquired through oral transmission from two urban outbreaks in Northeastern Brazil. PLoS Negl Trop Dis. (2010) 4:e711. doi: 10.1371/journal.pntd.0000711

54. de Góes Costa E, dos Santos SO, Sojo-Milano M, Amador ECC, Tatto E, Souza DSM, et al. Acute Chagas disease in the Brazilian Amazon: epidemiological and clinical features. Int J Cardiol. (2017) 235:1768. doi: 10.1016/j.ijcard.2017.02.101

55. Añez N, Crisante G, Rojas A, Dávila D. Brote de enfermedad de Chagas agudo de posible transmisión oral en Mérida, Venezuela. Bol Malariol y Salud Ambient. (2013) 53:1-11.

56. Cucunubá Pérez ZM. Vigilancia de Chagas agudo de posible transmisión oral en Colombia. XX Congr Latinoam Parasitol XV Congr Colomb Parasitol y Med Trop Simp Biomédica, Rev del Inst Nac Salud. (2011) 31:117-9.

57. Nicholls RS, Cucunubá ZM, Knudson A, Flórez AC, Montilla M, Puerta CJ, et al. Enfermedad de Chagas aguda en Colombia, una entidad poco sospechada. Informe de 10 casos presentados en el periodo 2002 a 2005. Biomédica. (2007) 27:8. doi: 10.7705/biomedica.v27i1.244

58. Añez N, Rojas A, Crisante G, Parra J, Vivas D, Parada H. Enfermedad de Chagas en Táchira. Nuevo brote oral oral Enfermedad de Chagas en el estado Táchira: Reporte de un nuevo brote por transmisión oral de Trypanosoma Cruzi en el occidente de Venezuela. Boletín Malariol Y Salud Ambient. (2018) 58:31-41.

59. Hernández C, Cucunubá Z, Flórez C, Olivera M, Valencia C, Zambrano $\mathrm{P}$, et al. Molecular diagnosis of Chagas disease in Colombia: parasitic loads and discrete typing units in patients from acute and chronic phases. PLoS Negl Trop Dis. (2016) 10:e0004997. doi: 10.1371/journal.pntd.0004997

60. Souza-Lima R de C de, Barbosa M das GV, Coura JR, Arcanjo ARL, Nascimento A da S, Ferreira JMBB, et al. Outbreak of acute Chagas disease associated with oral transmission in the Rio Negro region, Brazilian Amazon. Rev Soc Bras Med Trop. (2013) 46:510-4. doi: 10.1590/0037-8682-1367-2013

61. Noya BA de, Díaz-Bello Z, Colmenares C, Ruiz-Guevara R, Mauriello L, Muñoz-Calderón A, et al. Update on oral Chagas disease outbreaks in Venezuela: epidemiological, clinical and diagnostic approaches. Mem Inst Oswaldo Cruz. (2015) 110:377-86. doi: 10.1590/0074-02760140285

62. Alarcón de Noya B, Díaz-Bello Z, Colmenares C, Ruiz-Guevara R, Mauriello L, Zavala-Jaspe R, et al. Large urban outbreak of orally acquired acute Chagas disease at a school in Caracas, Venezuela. J Infect Dis. (2010) 201:130815. doi: $10.1086 / 651608$

63. Marques J, Mendoza I, Noya B, Acquatella H, Palacios I, Marques-Mejias M. ECG manifestations of the biggest outbreak of Chagas disease due to oral infection in Latin-America. Arq Bras Cardiol. (2013) 101:24954. doi: 10.5935/abc.20130144
64. Añez N, Crisante G, Rojas A, Segnini S, Espinoza-Álvarez O, Teixeira MMG. Update on Chagas disease in Venezuela during the period 20032018. A review. Acta Trop. (2020) 203:105310. doi: 10.1016/j.actatropica.2019. 105310

65. Nóbrega AA, Garcia MH, Tatto E, Obara MT, Costa E, Sobel J, et al. Oral transmission of Chagas disease by consumption of Açaí Palm Fruit, Brazil. Emerg Infect Dis. (2009) 15:653-5. doi: 10.3201/eid1504.0 81450

66. Hernández C, Cucunubá Z, Parra E, Toro G, Zambrano P, Ramírez JD. Chagas disease (Trypanosoma cruzi) and HIV co-infection in Colombia. Int J Infect Dis. (2014) 26:146-8. doi: 10.1016/j.ijid.2014. 04.002

67. Vaidian AK, Weiss LM, Tanowitz HB. Chagas' disease and AIDS. Kinetoplastid Biol Dis. (2004) 3:1-6. doi: 10.1186/1475-9292-3-2

68. Madalosso G, Pellini ACG, Vasconcelos MJ, Ribeiro AF, Weissmann L, Oliveira Filho GS, et al. Chagasic meningoencephalitis: case report of a recently included AIDS-defining illness in Brazil. Rev Inst Med Trop Sáo Paulo. (2004) 46:199-202. doi: 10.1590/S0036-4665200400 0400005

69. Begher S, Burgos JM, Bisio M, Levin MJ, Silva HMV, Schijman AG, et al. Case report: molecular identification of Trypanosoma cruzi I tropism for central nervous system in Chagas reactivation due to AIDS. Am J Trop Med Hyg. (2008) 78:294-7. doi: 10.4269/ajtmh.2008. 78.294

70. Almeida EA de, Ramos Júnior AN, Correia D, Shikanai-Yasuda MA. Coinfection Trypanosoma cruzi/HIV: systematic review (1980 - 2010). Rev Soc Bras Med Trop. (2011) 44:762-70. doi: 10.1590/S0037-86822011000 600021

71. Ramírez JD, Montilla M, Cucunubá ZM, Floréz AC, Zambrano P, Guhl F. Molecular epidemiology of human oral Chagas disease outbreaks in Colombia. PLoS Negl Trop Dis. (2013) 7:e2041. doi: 10.1371/journal.pntd.0002041

72. Messenger LA, Miles MA, Bern C. Between a bug and a hard place: Trypanosoma cruzi genetic diversity and the clinical outcomes of Chagas disease. Expert Rev Anti Infect Ther. (2015) 13:995-1029. doi: 10.1586/14787210.2015.1056158

73. Luquetti AO, Schmuñis GA. Diagnosis of Trypanosoma cruzi infection. In: American Trypanosomiasis. Elsevier (2010). p. 743-92. Available online at: https://linkinghub.elsevier.com/retrieve/pii/B9780123848765000289 (accessed February 20, 2021).

74. Ramírez JD, Guhl F, Rendón LM, Rosas F, Marin-Neto JA, Morillo CA. Chagas cardiomyopathy manifestations and Trypanosoma cruzi genotypes circulating in chronic chagasic patients. PLoS Negl Trop Dis. (2010) 4:e899. doi: 10.1371/journal.pntd.00 00899

Conflict of Interest: The authors declare that the research was conducted in the absence of any commercial or financial relationships that could be construed as a potential conflict of interest.

Publisher's Note: All claims expressed in this article are solely those of the authors and do not necessarily represent those of their affiliated organizations, or those of the publisher, the editors and the reviewers. Any product that may be evaluated in this article, or claim that may be made by its manufacturer, is not guaranteed or endorsed by the publisher.

Copyright (๐) 2021 Rincón-Acevedo, Parada-García, Olivera, Torres-Torres, ZuletaDueñas, Hernández and Ramírez. This is an open-access article distributed under the terms of the Creative Commons Attribution License (CC BY). The use, distribution or reproduction in other forums is permitted, provided the original author $(s)$ and the copyright owner(s) are credited and that the original publication in this journal is cited, in accordance with accepted academic practice. No use, distribution or reproduction is permitted which does not comply with these terms. 